\title{
Early Gallbladder Cancer: Clinical, Morphological, Therapeutic and Evolutionary Aspects
}

\author{
Berkane Salah", Abid Larbi \\ Unit of Visceral and Oncological Surgery, Bologhine Hospital, Algiers, Algeria \\ Email: "salahberkane07@yahoo.fr
}

Received September 23, 2013; revised October 20, 2013; accepted October 28, 2013

Copyright (c) 2013 Berkane Salah, Abid Larbi. This is an open access article distributed under the Creative Commons Attribution License, which permits unrestricted use, distribution, and reproduction in any medium, provided the original work is properly cited.

\begin{abstract}
Introduction: The early cancer of gallbladder is an entity which is not well recognized currently. It is a cancer which does not extend beyond the muscularis layer of the gallbladder and it is characterized in almost of cases by the absence of lymph node and visceral invasion. Patients and Method: We have conducted this retrospective study of all our cases of early gallbladder cancer treated in our surgical unit. We have studied these through clinical, morphological, therapeutical and evolutionary aspects. Results: Of 202 gallbladder carcinoma, 33 cancers were classified as early cancer. 25 were females and 8 were males. The mean age was 56.4 years (41 - 70 years). All patients were free of gallbladder cancer symptoms and all except one had normal CEA and CA19.9. 2 patients had synchronous tumors (one colonic cancer and one rectal cancer). For 16 patients, the diagnosis was done by ultrasonography and 17 by histological examination of the specimen removed for biliary lithiasis. 8 patients had PT1a tumor (confined only to mucosa) and 25 had PT1b tumor (tumor infiltration of the muscular layer). For 19 patients who benefited from extensive lymphadenectomy, only one (5.3\%) had lymph node infiltration. 16 patients had a simple cholecystectomy and in two cases, the cholecystectomy was associated with bile duct resection. 17 patients had hepatectomy with extensive lymphadenectomy. 2 patients had a simultaneous right colectomy and abdominoperineal resection and another one benefited from choledocal cyst resection. 3 patients benefited from stone removal from bile duct and two had tumor removal from bile duct (ruptured tumor in the bile duct). 1 patient (3.7\%) died in postoperative course (hospital mortality). In the follow-up period, 4 patients died from intercurrent causes. Two patients presented a recurrence at 14 and 36 months and died respectively at 19 and 42 months. One patient presented a bile duct cancer at 66 months. She died at 78 months after palliative treatment. Currently, 22 patients (66.7\%) are still alive without recurrence with mean and median survival of 53 and 31 months. Conclusion: Early gallbladder cancer is an entity which must be known by the radiologist and the surgeon. Recognized on time and well treated, early gallbladder cancer can be cured and its prognosis is excellent.
\end{abstract}

Keywords: Early Cancer; Gallbladder Cancer; Ultrasonography; Expert Radiologist; Surgical Treatment

\section{Introduction}

The early gallbladder cancer is an entity which is not well recognized currently. It is a tumor whose extension does not extend beyond the muscularis layer of the gallbladder and does not have frequent lymph node infiltration and metastatic spread [1]. Moreover, it represents a proportion of all gallbladder cancer which could be easily cured. In spite of modern morphologic examination and specifically an ultrasonography since twenty years, there is not a clear improvement in the diagnosis for this disease [2-4]. This form is often diagnosed after histological examination of specimen removed for biliary lithiasis. Making an

*Corresponding author. exact diagnosis before surgery has an importance to improve the prognosis of this fatal disease in its invasive form. Surgery is debated when the muscular layer is invaded (pT1b) between cholecystectomy and radical resection whereas the cholecystectomy is the best treatment for the pT1a (tumor confined to mucosa). In this article, we present our experience of patients who were managed in our unit during the fifteen last years and to analyze immediate and long-term prognosis of this disease.

\section{Patients and Method}

We analyzed all cases of our patients treated for early gallbladder cancer. We reported the clinical, morpho- 
logical, biological, surgical and evolutionary features of these patients. The histological specimen was reanalyzed for the cancer discovered after cholecystectomy done for biliary lithiasis. All the following features were asked to the histologist: histological form and grade (differentiation), parietal extension, perineural, vascular and node infiltration. In our unit, pT1a tumor (confined to mucosa) is treated by cholecystectomy and pT1b (muscular infiltration) is treated by cholecystectomy alone for the patient above 70 years and by bisugmental IV-V with fatal associated disease and extensive lymphadenectomy for patients under 70 years and without fatal associated disease. On the postoperative course, the patient is followed clinically, biologically (Ca 19.9 and CEA) and morphologically (ultrasound) each 3 months during 2 years and each 6 months during the following 2 years. After 5 years, we propose only clinically follow up. If a recurrence is diagnosed, a CT scan or MRI is done to have an exact diagnosis and if the disease is curable we propose a new surgery for resection and in the contrary only diversion is practiced. If there is no need of surgery we propose palliative chemotherapy.

\section{Results}

Of 202 gallbladder cancer resected since 1996, we report 33 patients with early form (16.3\%). There were 25 females and 8 males, with mean age of 56.4 years (41 - 70 years). No patient had any symptoms related to cancer before the surgery and physical examination were normal or related to lithiasis disease (pain, jaundice and palpable gallbladder in acute cholecystitis). 20 patients (60.6\%) had associated biliary lithiasis. One patient had a history of choledocal cyst since 25 years. The diagnosis was done in the preoperative course in 16 cases $(48.5 \%)$ by the radiologist with the ultrasonography and CT Scan. 3 last patients had an endoscopic ultrasonography. 17 cases were diagnosed on the histologist specimen. All of 24 carcino-embryonary antigen (CEA) and carbohydrate antigen 19.9 (CA19.9) measured out were normal except for one CA19.9 which was at $5618 \mathrm{UI} / \mathrm{ml}$ for patient with ruptured tumor in the bile duct and jaundice. One patient was treated for Hodgkin disease 10 years ago; 2 patients had their polypoid tumors known (diagnosed by ultrasonography) respectively 1year and ten years ago. The tumoral aspect was polypoid in 22 cases (66.7\%), thickening wall in 6 cases (18\%), unapparent form in 4 cases (12\%) and nodular in 1 case. 2 patients had ruptured tumor in the bile duct (pT1a and pT1b). Microscopically, all these cases were adenocarcinoma. 8 cases (24.2\%) were pT1a and 25 cases $(75.8 \%)$ were pT1b (Table 1: characteristics of 27 cases). 1 patient had a choledocal cyst diagnosed and followed by a gastroenterologist during 16 years. 16 patients benefited from a cholecystectomy associated with bile duct resection in two cases for a tumoral related cause and another had her choledocal cyst removed with a gallbladder. 2 patients who have had a cholecystectomy benefited from a lymphadenectomy. For 17 patients, IV-V bisugmental hepatectomy with extensive lymphadenectomy was done. 2 patients had respectively colonic and rectal resection simultaneously. 3 patients benefited from stone removal from bile duct. Only one patient presented node infiltration between 19 who benefited from lymphadenectomy (5.3\%). 24 patients (72.7\%) had one operation and 9 (27.8\%) two operations. The postoperative course was uneventful for 26 patients (78.8\%) and complicated in 7 cases $(21.2 \%)$. One patient (3\%) died from myocardial infarction (Table 2: surgical treatment). Two patients benefited from systemic chemotherapy, one because she had had cystic infiltrative node and another had associated liver metastatic lesion. On the long term follow up, one patient received external beam therapy for uterine cervix cancer diagnosed 2 years after the cholecystectomy. One patient died from a colon cancer recurrence at 15 months without any evident gallbladder cancer recurrence. 2 patients (6\%) presented a recurrence at respectively 14 and 36 months. They were initially treated by cholecystectomy. One benefited from bisugmental IV-V with lymphadenectomy and chemotherapy and died from a new recurrence at 19 months. The second patient had exploratory laparotomy and died at 42 months. One patient presented a bile duct cancer (upper part) at 66 months. She refused a surgery and died at 78 months. One patient died from acute diabetes complications at 56 months and other died from gastric hemorrhage secondary to gastric ulcus. One patient died from another disease at 67 months (portal high pressure). One was lost for follow up at 39 months. 22 patients (66.7\%) are still alive with mean survival of 51 months and median survival of 32 months. The global 3 and 5 year survival are respectively 53\% and 34\%. 11 patients (33.3\%) had more than 5 year survival and the two oldest had more than 10 years. No recurrence case occurred until nowadays for PTa tumor.

\section{Discussion}

The early cancer of gallbladder is a form which can be recognized by modern morphological examination but it is still diagnosed after surgery for biliary lithiasis. On clinical aspect, it is a silent disease (without any symptoms). This feature could explain this absence of diagnosis. Currently, it can be recognized in 2 situations:

- On preoperative course with ultrasonography [3-5].

- On the histological examination after cholecystectomy for biliary lithiasis [5-8].

For a clinician to make a diagnosis before a surgical step, he needs an expert radiologist who should be vigilant during ultrasound examination. There are two fundamentals lesions which are in favor of an early cancer: 
Table 1. Characteristics of patients.

\begin{tabular}{|c|c|c|c|c|c|c|c|c|c|c|c|}
\hline Case & Age & Sex & LB & $\mathrm{D}$ & M & M' & $\mathrm{L}$ & $\mathrm{D}(\mathrm{mm})$ & AP & CA19.9 & CEA \\
\hline 1 & 56 & $\mathrm{~F}$ & No & HD & & ADKNS & $\mathrm{F}$ & 40 & & NA & NA \\
\hline 2 & 56 & $\mathrm{~F}$ & No & UD & UNA & ADK (MIXED) & $\mathrm{C}$ & 30 & No & NA & NA \\
\hline 3 & 62 & $\mathrm{~F}$ & Yes & HD & $\begin{array}{l}P \\
P\end{array}$ & ADK (WD) & $\mathrm{F}+\mathrm{C}$ & $8-9$ & No & NA & NA \\
\hline 4 & 69 & $\mathrm{~F}$ & No & UD & $\begin{array}{l}P \\
P\end{array}$ & ADK (NS) & $\mathrm{F}$ & 30 & No & NA & NA \\
\hline 5 & 65 & $\mathrm{~F}$ & No & UD & $P$ & ADK (WD) & $\mathrm{C}$ & 15 & No & NA & NA \\
\hline 6 & 41 & $\mathrm{~F}$ & Yes & HD & P & ADK (MD) & - & - & No & NA & NA \\
\hline 7 & 57 & $\mathrm{~F}$ & Yes & HD & $\begin{array}{l}\text { TW } \\
\mathrm{P}\end{array}$ & ADK (MD) & $\mathrm{F}$ & $12-15-20$ & No & NA & NA \\
\hline 8 & 61 & $\mathrm{M}$ & No & UD & $\begin{array}{l}\mathrm{P} \\
\mathrm{P}\end{array}$ & ADK (WD) & $\mathrm{F}+\mathrm{C}$ & 20 & $\begin{array}{c}\text { No } \\
\text { Synchronous Colon }\end{array}$ & NA & NA \\
\hline 9 & 61 & $\mathrm{~F}$ & No & UD & & ADK (WD) PAP & C & 25 & cancer & $\mathrm{N}$ & $\mathrm{N}$ \\
\hline 10 & 63 & $\mathrm{~F}$ & Yes & HD & $\mathrm{P}$ & ADK (WD) PAP & $\mathrm{F}$ & $30-10$ & No & $\mathrm{N}$ & $\mathrm{N}$ \\
\hline 11 & 68 & M & Yes & UD & TW & ADK(WD) & $\mathrm{F}$ & 30 & No & $\mathrm{N}$ & $\mathrm{N}$ \\
\hline 12 & 62 & $\mathrm{~F}$ & Yes & HD & $\begin{array}{l}\mathrm{P} \\
\mathrm{P}\end{array}$ & ADK (WD) & $\mathrm{Ne}$ & 8 & No & E & $\mathrm{N}$ \\
\hline 13 & 48 & $\mathrm{~F}$ & Yes & HD & $\begin{array}{l}\mathrm{P} \\
\mathrm{P}\end{array}$ & ADK (WD) PAP & NP & 50 & No & $\mathrm{N}$ & $\mathrm{N}$ \\
\hline 14 & 46 & M & Yes & HD & P & ADK (MIXED) & $\mathrm{F}$ & 30 & No & $\mathrm{N}$ & $\mathrm{N}$ \\
\hline 15 & 56 & $\mathrm{~F}$ & Yes & HD & $1 \mathrm{~W}$ & ADK (WD) & UNA & 30 & No & $\mathrm{N}$ & $\mathrm{N}$ \\
\hline 16 & 70 & $\mathrm{~F}$ & No & UD & $\begin{array}{l}\mathrm{P} \\
\mathrm{P}\end{array}$ & ADK (WD) PAP & $\mathrm{F}$ & 40 & No & $\mathrm{N}$ & $\mathrm{N}$ \\
\hline 17 & 58 & $\mathrm{~F}$ & Yes & HD & $\begin{array}{c}\mathrm{P} \\
\mathrm{HN}\end{array}$ & ADK (WD) & $\mathrm{C}$ & 15 & No & $\mathrm{N}$ & $\mathrm{N}$ \\
\hline 18 & 60 & $\mathrm{M}$ & No & UD & $\begin{array}{c}\text { UNA } \\
\mathrm{P}\end{array}$ & ADK (WD) PAP & $\mathrm{F}$ & 50 & No & $\mathrm{N}$ & $\mathrm{N}$ \\
\hline 19 & 50 & $\mathrm{~F}$ & Yes & UD & $\begin{array}{l}P \\
P\end{array}$ & $\mathrm{ADK}(\mathrm{WD})+\mathrm{CM}$ & $\mathrm{C}$ & 20 & No & E & $\mathrm{N}$ \\
\hline 20 & 45 & $\mathrm{~F}$ & Yes & UD & $P$ & ADK (WD) & $\mathrm{F}$ & - & No & $\mathrm{N}$ & $\mathrm{N}$ \\
\hline 21 & 45 & $\mathrm{M}$ & Yes & HD & $P$ & ADK (MD) & $\mathrm{Ne}$ & 30 & BPM & $\mathrm{N}$ & $\mathrm{N}$ \\
\hline 22 & 58 & $\mathrm{M}$ & No & UD & $\begin{array}{l}\text { TW } \\
\mathrm{P}\end{array}$ & ADK (WD) & $\mathrm{F}$ & 35 & No & $\mathrm{N}$ & $\mathrm{N}$ \\
\hline 23 & 55 & $\mathrm{~F}$ & Yes & HD & $\begin{array}{l}\mathrm{P} \\
\mathrm{P}\end{array}$ & ADK (WD) & $\mathrm{Ne}$ & & No & $\mathrm{N}$ & $\mathrm{N}$ \\
\hline 24 & 60 & $\mathrm{~F}$ & Yes & HD & $\begin{array}{c}\mathrm{P} \\
\mathrm{HN}\end{array}$ & ADK (WD) & $\mathrm{F}$ & 25 & No & $\mathrm{N}$ & $\mathrm{N}$ \\
\hline 25 & 58 & $\mathrm{~F}$ & No & UD & $\begin{array}{l}\text { UNA } \\
\mathrm{P}\end{array}$ & ADK (WD) & $\mathrm{F}$ & 15 & URC + rectal cancer & $\mathrm{N}$ & $\mathrm{N}$ \\
\hline 26 & 47 & M & Yes & HD & $\begin{array}{c}\mathrm{P} \\
\mathrm{INA}\end{array}$ & ADK (WD) & $\mathrm{F}$ & - & No & $\mathrm{N}$ & $\mathrm{N}$ \\
\hline 27 & 56 & $\mathrm{~F}$ & No & UD & $\begin{array}{c}\text { UNA } \\
\mathrm{D}\end{array}$ & ADK (WD) & $\mathrm{Ne}$ & - & No & $\mathrm{N}$ & $\mathrm{N}$ \\
\hline 28 & 46 & $\mathrm{M}$ & No & UD & $\begin{array}{l}\mathrm{P} \\
\mathrm{P}\end{array}$ & ADK (WD) & $\mathrm{Ne}$ & - & No & $\mathrm{N}$ & $\mathrm{N}$ \\
\hline 29 & 60 & $\mathrm{~F}$ & No & UD & P & ADK (WD) & NP & 25 & No & $\mathrm{N}$ & $\mathrm{N}$ \\
\hline $30^{*}$ & 47 & $\mathrm{~F}$ & Yes & HD & P & ADKNS & TW & - & No & $\mathrm{N}$ & $\mathrm{N}$ \\
\hline 31 & 70 & $\mathrm{~F}$ & Yes & HD & TW & ADK (WD) & NO & - & No & NA & NA \\
\hline 32 & 54 & $\mathrm{~F}$ & Yes & HD & NOD & ADK (WD) & $\mathrm{P}$ & 20 & No & $\mathrm{N}$ & $\mathrm{N}$ \\
\hline 33 & 56 & $\mathrm{~F}$ & Yes & HD & $\mathrm{P}$ & ADKWD & TW & - & No & $\mathrm{N}$ & $\mathrm{N}$ \\
\hline
\end{tabular}

BPM: biliary pancreatic maljunction; BL: biliary lithiasis; D: diagnosis; E: elevated; F: fundus; C: corpus; Ne: neck. HD: histological discovery; CC: choledocal cyst; ADKWD: adenocarcinoma well-differentiated, M: Macroscopic aspect. M': microscopy; AMD: adenocarcinoma mean differentiated, ADKNS: adenocarcinoma not specified; L: location; N: normal; AP: associated pathology; Ca19.9: carbohydrate antigen 19.9; CEA: carcino-embryonary antigen; P: polypoid lesion; TW: thickened wall; NOD: nodal aspect; UD: ultrasound discovery UN: unapparent; URC: ulcerative.

- The most easier form to be detected is a polypoid form (Figure 1).

It is an image which is appended to the gallbladder wall. It has the same ultrasound-structure than the liver. It is immobile at the patient positions changes and does not give an acoustic shadow. This polyp could be single or multiple, with or without a pedicle. Some features could orient to the malignant nature, but the strong element is the polyp diameter (Table 2: malignant criterion of gallbladder polyp). If the polypoid form is easily recognized in a gallbladder without stones by the radiologist, this last could misinterpret the diagnosis when the gallbladder contains several stones. In this case, the tumor lesion could be hidden by stones and this diagnosis become difficult if not impossible. For this reason, the ultrasonography should be done on 2 different positions (lying on the back and on the side). With the lithiasis, acute cholecystitis with the inflammatory changes induced could impede the polyp detection by the radiologist.

- The second image of the early cancer is represented by

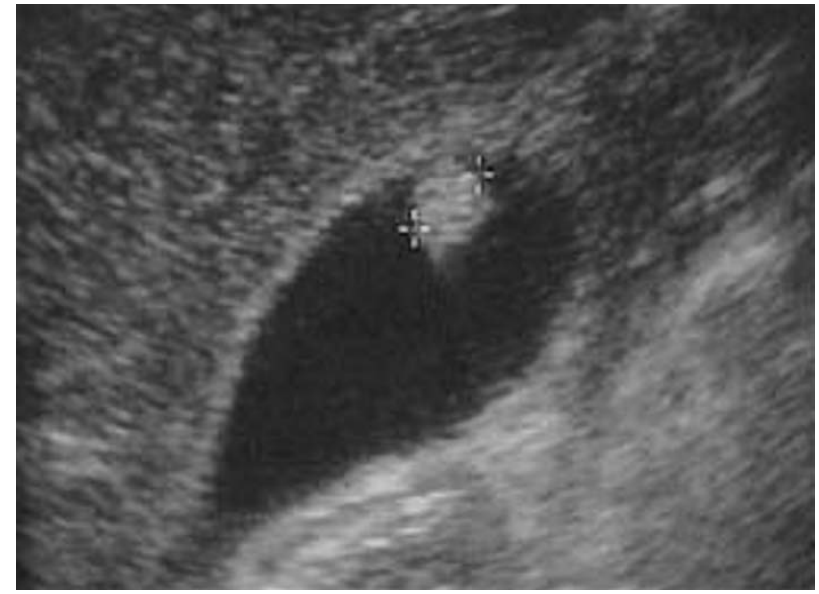

Figure 1. Image of polypoid lesion of the fundus of the gallbladder on ultrasound examination.

a thickening wall (infiltrative form). This abnormality could be localized or generalized in the gallbladder wall. 
Table 2. Therapeutic and evolutionary aspects.

\begin{tabular}{|c|c|c|c|c|}
\hline Case & Treatment & Postoperative course & Current status & Cause of death \\
\hline 1 & $\mathrm{CX}$ & Simple & AWD at 120 months & \\
\hline 2 & $\mathrm{CX}$ & Simple & AWD at 126 months & \\
\hline 3 & IV-V+ lymphadenectomy & Simple & AWD at 156 months & \\
\hline 4 & $\mathrm{CX}$ & Simple & DWD at 56 months ${ }^{*}$ & \\
\hline 5 & IV-V + lymphadenectomy & Simple & AWD at 140 months & \\
\hline 6 & IV-V + lymphadenectomy & External biliary fistula & LOF at 39 months & \\
\hline 7 & $\mathrm{CX}$ & Simple & AWD at 96 months & \\
\hline 8 & $\mathrm{CX}+$ colonic resection & Simple & DWD at 15 months ${ }^{*}$ & $\begin{array}{l}\text { Died from colonic } \\
\text { cancer recurrence }\end{array}$ \\
\hline 9 & $\mathrm{CX}$ & Simple & DWD at 78 months & Bile duct cancer \\
\hline 10 & $\mathrm{CX}$ & Simple & AWD at 81 months & \\
\hline 11 & $\begin{array}{l}\text { IV-V + lymphadenectomy + tumor } \\
\text { removal from bile duct }\end{array}$ & Residual tumor in bile duct & Alive at 69 months & \\
\hline 12 & $\mathrm{CX}$ & Simple & DOD at 19 months & Hepatic recurrence \\
\hline 13 & $\mathrm{CX}+$ bile duct resection & Simple & AWD at 68 months & \\
\hline 14 & $\mathrm{CX}$ & Simple & AWD at 72 months & \\
\hline 15 & $\mathrm{CX}$ & Simple & DOD at 42 months & Hepatic recurrence \\
\hline 16 & IV-V + lymphadenectomy + chemotherapy & Simple & DWD at 67 months & Hypertension portal? \\
\hline 17 & CX + IV-V + lymphadenectomy & Lymphatic fistula & DWD at 20 months & $\begin{array}{l}\text { Gastric ulcer Hemor- } \\
\text { rhage }\end{array}$ \\
\hline 18 & CX+ IV-V + lymphadenectomy & Postoperative death & POD & Myocardial infarction \\
\hline 19 & $\begin{array}{l}\text { IV-V + lymphadenectomy + tumor removal } \\
\text { from bile duct }\end{array}$ & External biliary fistula & AWD at 37 months & \\
\hline 21 & IV-V + lymphadenectomy & Simple & AWD at 37 months & \\
\hline 20 & $\mathrm{CX}+$ choledocal cyst resection & Simple & AWD at 36 months & \\
\hline 22 & IV-V + lymphadenectomy & Wound sepsis & AWD at 28 months & \\
\hline 23 & IV-V + lymphadenectomy & Hepatic necrosis & AWD at 28 months & \\
\hline 24 & $\mathrm{CX}+$ abdominoperineal resection & Simple & AWD at 25 months & \\
\hline 25 & IV-V + lymphadenectomy & Simple & AWD at 27 months & \\
\hline 26 & $\mathrm{CX}$ & Simple & AWD at 25 months & \\
\hline 27 & IV-V lymphadenectomy & Simple & AWD at 20 months & \\
\hline 28 & CX+IV-V+ lymphadenectomy & Simple & AWD at 18 months & \\
\hline 29 & IV-V+ lymphadenectomy + chemotherapy & Wound sepsis & AWD at 20 months & \\
\hline 32 & CX+ IV-V+ lymphadenectomy & Simple & AWD at 10 months & \\
\hline 31 & $\mathrm{CX}$ & Simple & AWD at 8 months & \\
\hline $30 *$ & $\mathrm{CX}+$ bile duct resection & Simple & AWD at 7 months & \\
\hline 33 & CX + IV - V + lymphadenectomy & Acute renal failure & AWD at 4 months & \\
\hline
\end{tabular}

AWD: alive without disease; DWD: died without disease; DOD: died with disease; LOF: lost for follow up; POD: postoperative death; CX: cholecystectomy; IV-V: bisugmental hepatectomy.

For the radiologist, each lesion of this kind detected with a meticulous examination of the gallbladder wall should be considered as a malignant lesion especially when it is limited to one part of the wall. The difficulty is represented by the presence of the acute cholecystitis. Onoyama [3] had used the ultrasonography for 53 patients with an early cancer. He was able to do the diagnosis in $34 \%$ of all form of cases. For the polypoid form, the preoperative diagnosis had been done in $75 \%$ of cases in the absence of lithiasis whereas it was possible only in
$38.1 \%$ of cases in presence of lithiasis. For the infiltrative form (thickening wall), the diagnosis was done respectively in $5.9 \%$ et $0 \%$. Tsuchiya [5] founds the same difficulty in his series in presence of lithiasis and with the thickening wall. The early cancer of the gallbladder is suspected between the patients of the first group (INF0) of the Japanese Society of biliary surgery (JSBS) [9]. In our series and with the same examination (trans-cutaneous ultrasonography), the preoperative diagnosis have been done only in 16 cases (48.5\%) and all these cases were 
polypoid form. Between these, 5 cases had lithiasis and 5 did not have. The contribution of the CT scan (Figure 2) for the diagnostic is good and the endoscopic ultrasonography seems also to be an excellent tool if well executed $[4,10]$. The endoscopic ultrasonography should be done after the trans-cutaneous ultrasonography (second intention). This examination could show the degree of parietal extension and then made a difference between an early form (pT1) and invasive form (pT2 and pT3) of gallbladder cancer [10]. But, few studies had been done with this examination currently. In our experience, we have started the practice of the endoscopic ultrasonography and the preliminary results are encouraging.

The second possibility to recognize this form of gallbladder cancer is represented by the histological examination of gallbladder specimen resected for biliary lithiasis and it is more common until nowadays. It is well known that in the almost cases, the surgeon can perfectly suspect this cancer after opening the gallbladder. It is macroscopically apparent on the mucosa of the gallbladder in almost cases $[2,3,6,7,11,12]$. In our series, it was the case (macroscopically visible) in 29 cases (87.8\%) after the opening of the gallbladder by the surgeon. It was easy for a polypoid form and difficult for the thickening form especially when it is associated with cholecystitis. This fact is very important for the treatment and binds the surgeon to open the gallbladder at the end of the intervention and scrutinize the gallbladder mucosa and its wall [8] (Figure 3). 4 unapparent forms (mucosa apparently normal in case of acute cholecystitis) were encountered in our series (intraepithelial adenocarcinoma) and not recognized. For us, each resected gallbladder should be opened and carefully examined at the end of intervention and before the abdominal closure or port ablation by the surgeon. The specimen should have a histological ex-

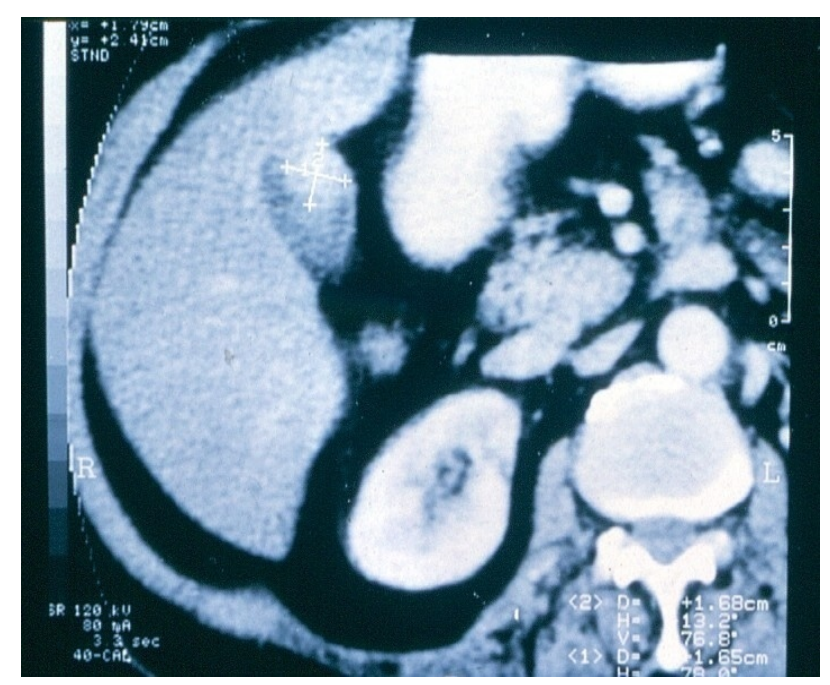

Figure 2. Image of polypoid lesion of the fundus of the gallbladder on CT scan examination.

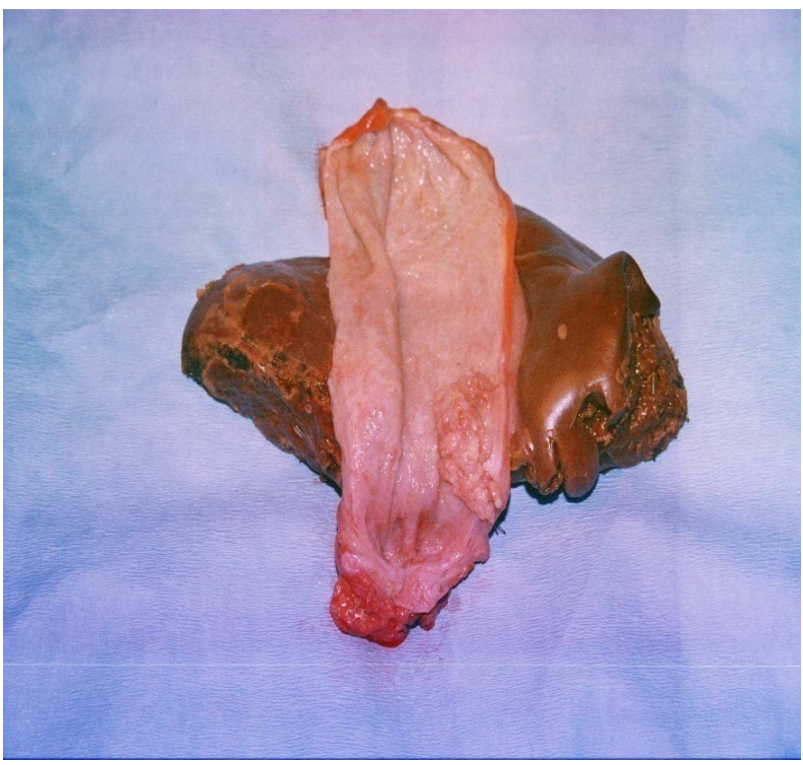

Figure 3. Specimen of PT1b gallbladder cancer.

amination in a short delay. All parts of the gallbladder must be examined. In this series, we encountered infiltrative cystic stump in which high degree of dysplasia was found after the second operation done 2 months later in patient who benefited from bile duct resection after a cholecystectomy.

The treatment of early gallbladder cancer is surgery [6,11-15]. The best treatment is cholecystectomy which is curative for the majority of the authors [8,16-19]. For others, the cholecystectomy is sufficient only for the pT1a form (mucosal tumor). A radical resection (cholecystectomy associated with hepatectomy and lymphadenectomy) is indicated for the pT1b form (involvement of the muscularis layer) [20-22]. This controversy seems to found its explanation in the fact that these authors find a node extension in the PT1b form $[14,20]$. For Shimizu et al. [23] and Shukla et al. [24], the best treatment for PT1b is a radical cholecystectomy and then the reoperation is recommended. In our series, two patients with pT1b tumor presented recurrence at 14 and 36 months (6\%) after cholecystectomy alone and one have an infiltrative cystic node. No patient has presented any recurrence until now after radical resection for PT1b. Another explanation of this controversy could be the imperfection of the histological examination and some cases of the PT1b are in fact invasive form PT2 or even PT3 for which the cholecystectomy is insufficient. We have an example with patient who had 2 foci of tumor, one PT1b in the corpus of the gallbladder and another PT3 in the neck (data not shown). M. A. Abramson et al. [25] demonstrated that the greatest benefit in gained life-years is achieved for the youngest ages having radical resection. We agree with this view. For us, if the patient with pT1b tumor is 70-year-old or less and without a serious general disease and a long life 
expectancy, the radical surgery (re-resection) is indicated but if the age is upon 70 years or the patient has a serious general disease or a short life expectancy, the radical surgery in must be avoided. It is what we have chosen for our patient. A recent and large study has reported a good prognosis with radical surgery which contains hepatectomy and lymphadenectomy [25].

If the diagnosis is done in the preoperative step, the radical approach is indicated for us when we do not know infiltrative degree in the gallbladder wall. We started recently the use of endoscopic ultrasonography after trans-cutaneous ultrasonography in the aim to explore the wall extension and to not misinterpret an invasive form (PT2 or PT3) and make a difference between PT1a and PT1b. In the opposite case, the decision is difficult. Should we do a simple cholecystectomy or a radical resection? During the intervention, the surgeon could lead himself on the aspect of the serous layer for the tumor located on peritoneal side of the gallbladder. If it is an early form, the serous layer is normal but if it is the contrary (retraction of serous surface and white color...), invasive form must be suspected. If the doubt persists, the surgeon could practice a radical cholecystectomy if the patient can support this surgery. If the diagnosis is done after the opening of the gallbladder at the end of the operation, it is wiser to wait the definitive histological examination. If it is a pT1a cancer the cholecystectomy is sufficient. The invasive form (PT2-T3) and PT1b needs a second operation $[6,8]$. The quality of the histological examination is fundamental. The histologist should verify with a multiple sections if there is not foci of invasive tumor or a lesion in the Rokitanski-Aschoff sinus and for a lesion near cystic channel (tumor of the neck) in which a surgeon would have cut in the tumor [8]. Others criterion are perineural infiltration and vascular embolus which must be noted in the histological report. If the patient presents a node infiltration, we advocate a systemic chemotherapy as adjuvant therapy. We have used systemic chemotherapy for two of our (one with infiltrative node and one with small liver metastasis).

The postoperative course is simple in almost cases. The prognosis of this form of gallbladder cancer is excellent with a cholecystectomy $[2,11,14,16,18]$ and radical cholecystectomy. The 5 year survival fluctuates between $70 \%$ and $100 \%$ [2,7,8,11,14,16-21,26]. In our experience, we encountered one death (radical cholecystectomy) not related to the surgery (myocardial infarction). It is one of the favorable form in which we can talk about a complete recovery after a treatment, even if late recurrences have been reported in the literature [11,21].

\section{Conclusion}

There is a clear evidence through our experience and literature that the early gallbladder cancer could be rec- ognized in the preoperative course with the modern morphologic examination (trans-cutaneous ultrasonography, CT scan, endoscopic ultrasonography...) and on histological specimen. This form is without gallbladder cancer symptoms, and tumor markers (CEA and CA19.9) are usually normal. A polypoid is the easy recognizable morphological form by the radiologist. The thickened wall form is more difficult to be diagnosed on ultrasonography. We focus on the fact that all the specialized teams (radiologist, surgeon, gastroenterologist, histologist...) are concerned in order to have a well conducted diagnosis approach and treatment. The radiologist is the key-element in this way. The trans-cutaneous ultrasonography examination (referential examination) should be done in minimally two positions in order to not misinterpret a tumoral lesion. Each infiltrative lesion (thick wall) must be addressed to a surgeon for a cholecystectomy. For the polypoid lesion, each polyp whose the diameter is above $10 \mathrm{~mm}$ is an indication of a cholecystectomy. Follow-up with ultrasonography for a lesion under $10 \mathrm{~mm}$ is indicated (Figure 4). The surgeon must do a simple cholecystectomy in case of PT1a and radical resection for the PT1b for the majority of cases. Well treated, almost of these patients will be cured.

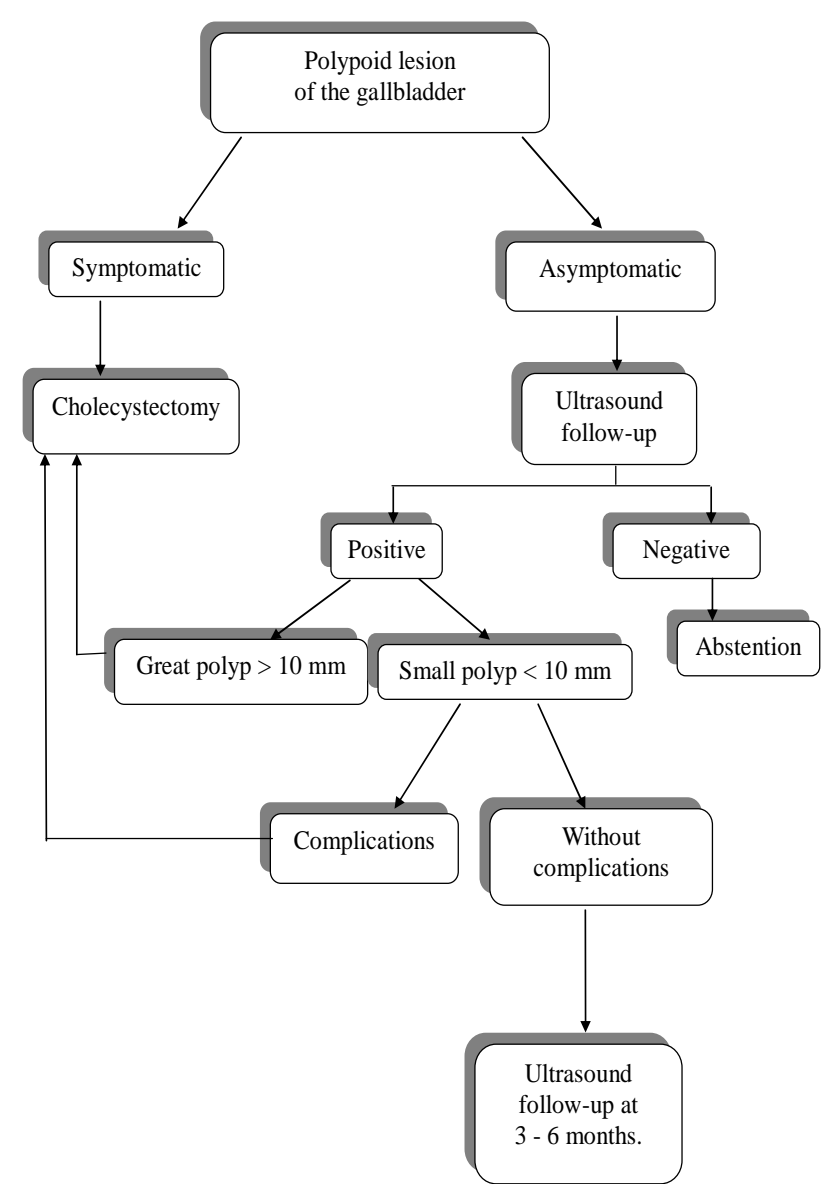

Figure 4. Algorithm of gallbladder polyp follow-up. 


\section{REFERENCES}

[1] R. Mizumoto, Y. Ogura and T. Kusuda, "Definition and Diagnostic of Early Cancer of Biliary Tract,” HepatoGastroenyterology, Vol. 40, No. 1, 1993, pp. 69-77.

[2] A. Koga, S. Yamaguchi, Y. Izumi and N. Hamanaka, "Ultrasonographic Detection of Early and Curable Carcinoma of the Gallbladder,” British Journal of Surgery, Vol. 72, No. 9, 1988, pp. 728-730. http://dx.doi.org/10.1002/bjs.1800720919

[3] H. Onoyama, M. Yamamoto, M. Takada, T. Urakawa, T. Ajiki, I. Yamada, T. Fujita and Y. Saitoh, "Diagnostic Imaging of Early Gallbladder Cancer: Retrospective Study of 53 Cases,” World Journal of Surgery, Vol. 23, No. 7, 1999, pp. 708-712. http://dx.doi.org/10.1007/PL00012373

[4] K. Ouchi, M. Suzuki, S. Saijo, K. Ito and S. Matsuno, "Do Recent Advances in Diagnosis and Operative Management Improve the Outcome of Gallbladder Carcinoma,” Surgery, Vol. 113, 1993, pp. 324-329.

[5] Y. Tsuchiya, "Early Carcinoma of the Gallbladder: Macroscopic Features and Us Findings,” Radiology, Vol. 179, No. 1, 1991, pp. 171-175.

[6] O. Glehen, O. Czyglik, A. D. V. Donsbeck, S. Isaak, F. N. Gilly, Y. François and J. Vignal, "Cancers Vésiculaires de Découverte Fortuite,” Annales de Chirurgie, Vol. 125, No. 2, 2000, pp. 137-143. http://dx.doi.org/10.1016/S0001-4001(00)00114-8

[7] E. Kraas, D. Frauenschuh and S. Farke, "Intraoperative Suspicion of Gallbladder Carcinoma in Laparoscopic Surgery: What to Do?” Digestive Surgery, Vol. 19, No. 6, 2002, pp. 489-493. http://dx.doi.org/10.1159/000067602

[8] Y. Shirai, K. Yoshida, K. Tsukada and T. Muto, "Unapparent Carcinoma of the Gallbladder," Annals of Surgery, Vol. 215, 1992, pp. 326-331. http://dx.doi.org/10.1097/00000658-199204000-00004

[9] F. Iida, S. Kajikawa and N. Horigone, "Evaluation of Imaging Examination for Hepatic Invasion of Carcinoma of the Gallbladder and Post Operative Outcome,” Journal of the American College of Surgeons, Vol. 180, No. 1, 1995, pp. 72-76.

[10] T. Azuma, T. Yoshikawa, T. Araida and K. Takasaki, "Differential Diagnosis of Polypoid Lesions of the Gallbladder by Endoscopic Ultrasonography," American Journal of Surgery, Vol. 181, No. 1, 2001, pp. 65-70.

http://dx.doi.org/10.1016/S0002-9610(00)00526-2

[11] R. M. Appleman, C. G. Morlock, D. C. Dahlin and M. A. Adson, "Long Term Survival in Carcinoma of the Gallbladder,” Surgical, Gynecology and Obstetric, Vol. 117, 1963, pp. 459- 464.

[12] X. de Aretxabala, I. Roa, L. Burgos, J. C. Araya, L. Fonseca, I. Wistuba and P. Flores, "Gallblader Cancer in Chile. A Report on 54 Potentially Resectable Tumors,” Cancer, Vol. 69, No. 1, 1992, pp. 60-65. http://dx.doi.org/10.1002/1097-0142(19920101)69:1<60:: AID-CNCR2820690112>3.0.CO;2-N

[13] H. Isman and M. Brisard, "L'espoir de Guérison du Cancer de la Vésicule Biliaire. Arguments Pour une Conception Nouvelle des Stades Précoces,” Journal de
Chirurgie, Vol. 121, No. 1, 1984, pp. 51-55.

[14] Y. Ogura, R. Mizumoto, S. Isaji, T. Kusuda, S. Matsuda and M. Tabata, "Radical Operations for Carcinoma of the Gallbladder: Present Status in Japan,” World Journal of Surgery, Vol. 15, No. 3, 1991, pp. 337-343. http://dx.doi.org/10.1007/BF01658725

[15] K. Ouchi, M. Suzuki, T. Tominaga, S. Saijo and S. Matsuno, "Survival after Surgery for Cancer of the Gallbladder,” British Journal of Surgery, Vol. 81, No. 11, 1994, pp. 16655-1657. http://dx.doi.org/10.1002/bjs.1800811131

[16] T. Wakai, Y. Shirai, N. Yokoyama, S. Nagakura, H. Watanabe and K. Hatakeyama, "Early Gallbladder Carcinoma Does Not Warrant Radical Resection,” British Journal of Surgery, Vol. 88, No. 5, 2001, pp. 675-678. http://dx.doi.org/10.1046/j.1365-2168.2001.01749.x

[17] M. Yamamoto, H. Onoyama, T. Ajiki, I. Yamada, T. Fujita and Y. Saitoh, "Surgical Results of Operation for Carcinoma of the Gallbladder," Hepato-Gastroenterology, Vol. 46, No. 27, 1999, pp. 1552-1556.

[18] K. Yamaguchi and M. Tsuneoshi, "Subclinical Gallbladder Carcinoma," American Journal of Surgery, Vol. 163, No. 4, 1992, pp. 382-386. http://dx.doi.org/10.1016/0002-9610(92)90038-S

[19] K. Yamaguchi, K. Chijiiwa, S. Saiki, K. Nishihara, M. Takashima, K. Kawakami and M. Tanaka, "Retrospective Analysis of 70 Operations for Gallbladder Carcinoma," British Journal of Surgery, Vol. 84, No. 2, 1997, pp. 200-204. http://dx.doi.org/10.1002/bjs.1800840217

[20] H. Kinoshita, K. Hashiro, M. Hashimoto, T. Kodama, K. Nishimura, M. Kawataba, S. Furukawa, T. Tamae, J. Nagashima, M. Hara, H. Imayama and S. Aoyagi, “Clinicopathological Evaluation of Surgical Treatment for Early Gallbladder Cancer,” Kurume Medical Journal, Vol. 48, No. 4, 2001, pp. 267-271. http://dx.doi.org/10.2739/kurumemedj.48.267

[21] G. Wagholikar, D. Gajanan, A. Behari, N. Krishnani, A. Kumar, S. S. Sadiq, R. Saxena and V. K. Kapoor, "Early Gallbladder Carcinoma," Journal of the American College of Surgeons, Vol. 194, No. 5, 2002, pp. 137-141. http://dx.doi.org/10.1016/S1072-7515(01)01136-X

[22] E. Yildrim, O. Celen, K. Gulben and U. Berberuglu, “The Surgical Management of Incidental Gallbladder Carcinoma,” European Journal of Surgery, Vol. 31, No. 1, 2005, pp. 45-52.

[23] T. Shimizu, Y. Arima, S. Yokomuro, H. Yoshida, Y. Mamada, T. Numura, N. Taniai, T. Aimoto, Y. Nakamura, Y. Mizuguchi, Y. Kawahigashi, E. Uchida, K. Akimaru and T. Tajiri, "Incidental Gallbladder Cancer Diagnosed during and after Laparoscopic Cholecystectomy,” Journal of Nippon Medical School, Vol. 73, 2006, pp. 136-140.

[24] P. J. Shukla, G. Barreto, A. Karade and S. V. Shrikhande, "Revision Surgery for Incidental Gallbladder: Factors Influencing Operability and Further Evidence for pT1b Tumors," HPB, Vol. 10, No. 1, 2008, pp. 43-47. http://dx.doi.org/10.1080/13651820701867794

[25] M. A. Abramson, P. Pandharipande, D. Ruan, J. S. Gold and E. E. Whang, "Radical Resection for pT1b Cancer: A 
Decision Analysis,” HPB, Vol. 11, No. 8, 2009, pp. 656663. http://dx.doi.org/10.1111/j.1477-2574.2009.00108.x

[26] D. M. Hari, J. H. Howard, A. M. Leung, C. G. Chui, M. S. Sim and A. J. Bilchik, "A 21-Year Analysis of Stage I
Gallbladder Carcinoma: Is Cholecystectomy Alone Adequate?” HPB, Vol. 15, No. 1, 2013, pp. 40-48.

http://dx.doi.org/10.1111/j.1477-2574.2012.00559.x 